\title{
THE EFFECTS OF FINISH ROLLING TEMPERATURE AND NIOBIUM MICROALLOYING ON THE MICROSTRUCTURE AND PROPERTIES OF A DIRECT QUENCHED HIGH-STRENGTH STEEL
}

\begin{abstract}
This paper comprehends the effects of finish rolling temperature (FRT) and Nb-microalloying on the microstructural evolution and resultant properties of a low carbon direct quenched steel in the yield strength category of $\geq 900 \mathrm{MPa}$. Results indicate that a decrease in FRT close to $\mathrm{A}_{\mathrm{r} 3}$ temperature significantly influenced the microstructure following phase transformation, especially at the subsurface $(\sim 50-400 \mu \mathrm{m})$ of the rolled strip. On decreasing the FRT, the subsurface microstructure revealed a fine mixture of ferrite and bainite obviously as a result of strain-induced transformation, whereas the structure at the centreline remained essentially martensitic. Further, Nb-microalloying promoted the formation of ferrite and bainite even at higher FRTs, thus influencing the mechanical properties. The microstructures of the hot-rolled strips were further corroborated with the aid of CCT diagrams.

Keywords: Direct quenching, hot rolling, Nb-microalloying, microstructure, $\mathrm{CCT}$ diagram
\end{abstract}

\section{Introduction}

In recent years, high-strength steels with yield strength steels in the range 800 to $1100 \mathrm{MPa}$ produced using thermomechanical rolling and direct quenching (TM-DQ) have become interesting materials for structural applications, because these steels can exhibit good combinations of mechanical properties and weldability [1-3]. The microstructures of these steels often comprise of lower bainite and/or auto-tempered martensite $[1,4,5]$. In the case of TM-DQ steels, cold bending is an important method of forming in applications such as containers and crane booms and often, bendability is considered a vital usability property for inservice applications of these high-strength steels. The bendability is generally measured as the minimum radius ( $r$ ) to the strip thickness $(\mathrm{t})$ that the steel can tolerate without the appearance of surface defects during bending to an angle of $90^{\circ}$ in three-point bending test [6]. The bendability improves remarkably when the steel hardness just below the surface is marginally lower than in the bulk owing to the presence of a mixture of ferritic and granular bainitic microstructure near the surface, in contrast to a generally bainitic and/or martensitic microstructure in the core of the sample, as the condition for the onset of strain localization and shear band formation was thereby significantly averted $[7,8]$. It has also been shown that the near-surface properties, i.e. the properties at the depth in the range $1-6 \%$ of the total sheet thickness from the surface, govern the bendability [8].

Hence, it is important to ascertain the factors leading to the formation of a relatively soft microstructure at the surface and underlying mechanisms in order to impart the best possible combinations of yield strength, toughness, ductility and bendability in these high-strength steels. Specific TM processing steps were developed in order to obtain a relatively hard core with a bainite/ martensite microstructure and a softer ferrite/granular bainite surface layer obviously as a result of controlled strain induced transformation, the details of which are described elsewhere [8]. The phase transformation characteristics were dependent not only on the chemical composition [9-12], but also the extent of austenite pancaking and FRT $[9,13]$

An in-depth study on the influence of FRT and niobium microalloying on the subsequent phase transformation characteristics, hardenability, properties and microstructural features, in particular the circumstances leading to the desired manifestation of relatively softer surface microstructure of some pilot scale processed and direct quenched high-strength steel strips, has recently been conducted at the authors' laboratory [7]. This paper presents a comprehensive summary of the results with special emphasis on the hardenability and phase transformation aspects verified through CCT dilatation measurements to understand the microstructure development and related hardness as a function of austenite state (FRT) and cooling rate. Additions of niobium are known to control the grain size (in reheating), influence the hardenability (in quenching) and impart precipitation hardening in tempering stage. Thus, supplementing additional information using meticulously planned dilatometer experiments in Gleeble is considered important for interpretation of the phase transformation characteristics during actual pilot scale rolling.

\footnotetext{
UNIVERSITY OF OULU, MATERIALS ENGINEERING AND PRODUCTION TECHNOLOGY, OULU, FINLAND

* SSAB EUROPE OY, RAAHE, FINLAND

\# Corresponding author: antti.kaijalainen@oulu.f
} 


\section{Materials and experimental procedures}

In order to elucidate the influence of niobium, two low-alloy steels of nearly similar compositions (base: $0.1 \mathrm{C}-0.2 \mathrm{Si}-1.1 \mathrm{Mn}-$ $0.15 \mathrm{Mo}-0.03 \mathrm{Ti}-0.002 \mathrm{~B}$ in wt.\%) without (Steel A) or with $0.04 \%$ $\mathrm{Nb}$ (Steel B) were subjected to hot rolling at pilot scale followed by direct quenching to room temperature at a rate of about 50 $70^{\circ} \mathrm{C} / \mathrm{s}$ depending on thickness. The thermomechanical rolling comprised typical recrystallization controlled rolling followed by controlled rolling in $\mathrm{T}_{\mathrm{nr}}$ (no-recrystallization) regime according to a proprietary schedule. The finish rolling temperature (FRT) was varied in the range $820-950^{\circ} \mathrm{C}$ leading to a final thickness of $6 \mathrm{~mm}$ (Steel A; without $\mathrm{Nb}$ ) and $8 \mathrm{~mm}$ (Steel B; with $0.04 \mathrm{Nb}$ microalloying). The steel codes were applied to describe the chemical composition of the steel (A or B) and the finish rolling temperature $\left(950-820^{\circ} \mathrm{C}\right)$.

To generate dilatation data for constructing the CCT diagrams using a Gleeble 3800 simulator, samples from both the steels were initially solution treated at $1250^{\circ} \mathrm{C}$ for 2 hours followed by water quenching. Cylindrical specimens of $6 \mathrm{~mm}$ dia $\times 9 \mathrm{~mm}$ for linear cooling rates $2-40^{\circ} \mathrm{C} / \mathrm{s}$ and $4 \mathrm{~mm}$ dia $\times 6$ $\mathrm{mm}$ for cooling rates $50^{\circ} \mathrm{C} / \mathrm{s}$ and $70^{\circ} \mathrm{C} / \mathrm{s}$ were used for the CCT dilatation tests. Two types of dilatation tests were made: with or without prior strain. In the case of straining, samples were heated at $10^{\circ} \mathrm{C} / \mathrm{s}$ to $1100^{\circ} \mathrm{C}$, held for $2 \mathrm{~min}$, cooled to $850^{\circ} \mathrm{C}$, held 15 $\mathrm{s}$, and then compressed with three hits each having a strain of $\sim 0.2$ at a strain rate of $1 / \mathrm{s}$. The specimens were then held $5 \mathrm{~s}$ before cooling at various linear rates in the range $2-70^{\circ} \mathrm{C} / \mathrm{s}$. For comparison, another set of specimens was reheated in a similar manner, held for $2 \mathrm{~min}$ prior to cooling at different linear cooling rates $2-70^{\circ} \mathrm{C} / \mathrm{s}$. These two sets of simulation experiments were meant to simulate quenching after hot rolling with high finish rolling temperatures and after controlled rolling finishing in the $\mathrm{T}_{\mathrm{nr}}$ regime. Different phase transformation temperatures were identified from the temperature-dilatation data based on the deviation from the linear thermal contraction.

A general characterization of the transformation microstructures was performed with a laser scanning confocal microscope (LSCM) and a field emission scanning electron microscope (FESEM) (Ultra plus, Zeiss) on specimens etched with Nital or picric acid [14]. The typical prior austenite grain structure was quantified at the quarter-thickness by measuring the mean linear intercepts along the rolling direction (RD) and normal direction (ND). Based on these measurements, the total reduction below the recrystallization temperature $\left(\mathrm{R}_{\text {tot. }}\right)$ were determined using the equation given in Ref. [15]. Supplementary microstructure characterizations were performed using the Oxford-HKL acquisition and analysis software following the microstructural classification described in Ref. [16]. For the electron backscatter diffraction (EBSD) measurements, the FESEM was operated at $10 \mathrm{kV}$ and the step size was $0.2 \mu \mathrm{m}$. Macrohardness was measured using a Duramin-A300 (Struers) using a $50 \mathrm{~N}$ load. Mechanical property evaluation included tensile testing in accord with the European standard EN 10002 and Charpy-V impact testing was performed at $-60^{\circ} \mathrm{C}$ using sub-size specimens of $\mathrm{t} \times 10 \times 55 \mathrm{~mm}^{3}$. Three-point bending tests were performed in an Ursviken Optima 100 bending machine up to a $90^{\circ}$ bending angle. Plate specimens, $\mathrm{t} \times 300 \times 300 \mathrm{~mm}^{3}$, were bent with the bend axes parallel to both the transverse and rolling directions. The die opening width (W) employed was $75 \mathrm{~mm}$ for the $6 \mathrm{~mm}$ thick specimens and $100 \mathrm{~mm}$ for the $8 \mathrm{~mm}$ thick specimens. The punch radius ( $\mathrm{r}$ ) varied from $8 \mathrm{~mm}$ to $50 \mathrm{~mm}$. After bending, the quality of the bent surface was examined by a visual inspection procedure, as described in Ref. [6]. On the basis of this inspection, the minimum usable bending radius was determined.

\section{Results}

\subsection{Hot rolling trials}

\subsubsection{Microstructure}

Finish rolling temperature is important through its effect on the austenite grain structure, which strongly influences the mechanical properties of the final product. Whereas the higher strength of DQ steels compared to reheat quenched plates has been attributed to the refinement of the martensite structure, an increased dislocation density of the martensite and improvement in toughness has been found to be associated with the ausforming leading to a shortening and randomization of the martensitic laths. LSCM images of the prior austenite grain structure of investigated steels in RD-ND section are shown in Fig. 1. The austenite grain shape measurements based on linear intercept measurements are summarized in Table 1. For Steel A (without Nb), the extent of pancaking following rolling in the $\mathrm{T}_{\mathrm{nr}}$ regime increased with the decrease in FRT from 950 to $820^{\circ} \mathrm{C}$, as also confirmed by the austenite structures in RD-ND section, resulting in an estimated $\mathrm{R}_{\text {tot }}$ ranging from $16 \%$ to $71 \%$, respectively. Decreasing the finish rolling temperature below the non-recrystallization

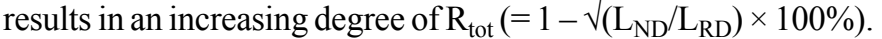
In contrast, Steel B bearing $0.04 \mathrm{wt} . \% \mathrm{Nb}$, austenite grains were pancaked even at the high FRT of $920^{\circ} \mathrm{C}$ : $\mathrm{R}_{\text {tot }}$ was approx. $52 \%$ at this temperature and increased to approx. 64\% at lower FRTs in the range $880^{\circ} \mathrm{C}$ down to $820^{\circ} \mathrm{C}$.

TABLE 1

Mean linear intercept measurements of the prior austenite grain structure along the two principal directions relative to the rolling direction at the quarter-thickness of the strip. These are compared with the total reduction $\left(\mathrm{R}_{\mathrm{tot}}\right)$. The $95 \%$ confidence limits are also given

\begin{tabular}{|c|c|c|c|}
\hline \hline Specimen & $\overline{\boldsymbol{L}}_{\boldsymbol{R D}}, \boldsymbol{( \boldsymbol { \mu m } )}$ & $\overline{\boldsymbol{L}}_{\boldsymbol{N D}} \boldsymbol{,}(\boldsymbol{\mu \mathbf { m } )}$ & $\mathbf{R}_{\text {tot }}(\mathbf{\%})$ \\
\hline A950 & $14.9 \pm 1.3$ & $10.4 \pm 0.7$ & 16 \\
\hline A920 & $14.9 \pm 1.3$ & $5.8 \pm 0.3$ & 38 \\
\hline A850 & $16.0 \pm 1.4$ & $3.7 \pm 0.2$ & 52 \\
\hline A830 & $21.5 \pm 1.6$ & $2.5 \pm 0.1$ & 66 \\
\hline A820 & $26.2 \pm 2.2$ & $2.2 \pm 0.1$ & 71 \\
\hline B920 & $16.2 \pm 1.2$ & $3.7 \pm 0.2$ & 52 \\
\hline B880 & $19.8 \pm 1.7$ & $2.6 \pm 0.1$ & 64 \\
\hline B840 & $19.4 \pm 1.6$ & $2.5 \pm 0.1$ & 64 \\
\hline B820 & $19.5 \pm 1.6$ & $2.5 \pm 0.1$ & 64 \\
\hline
\end{tabular}



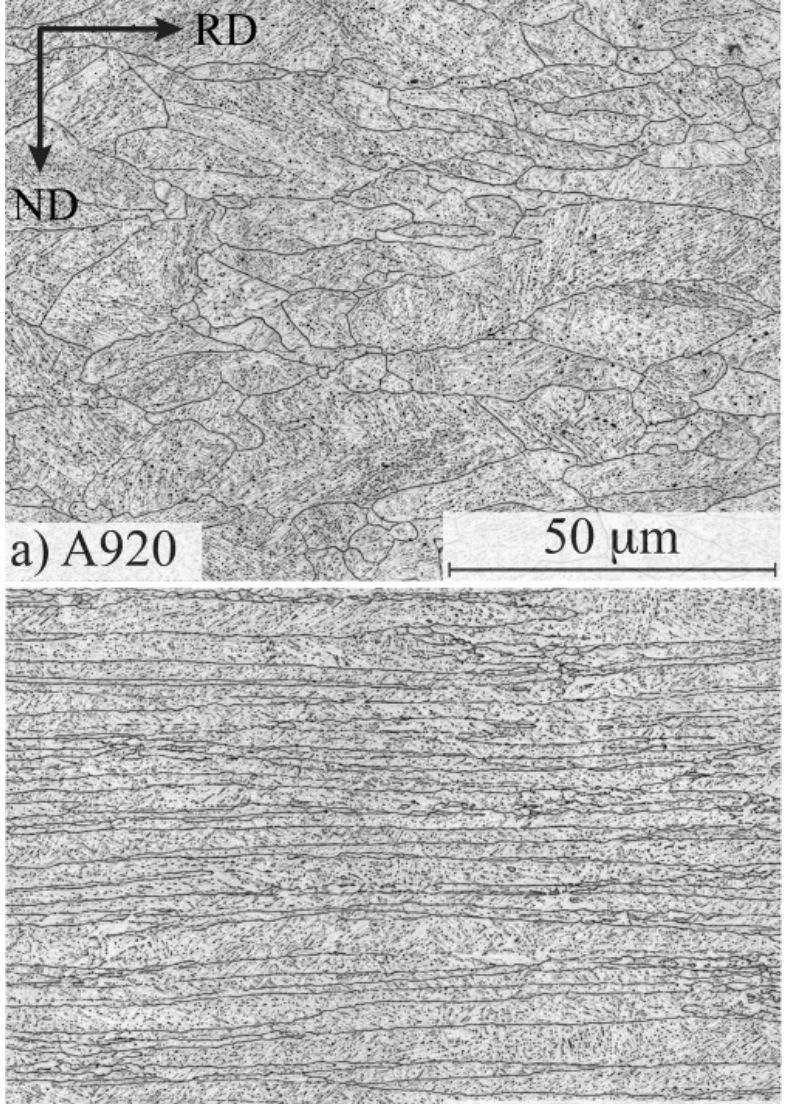

b) A 820

$50 \mu \mathrm{m}$

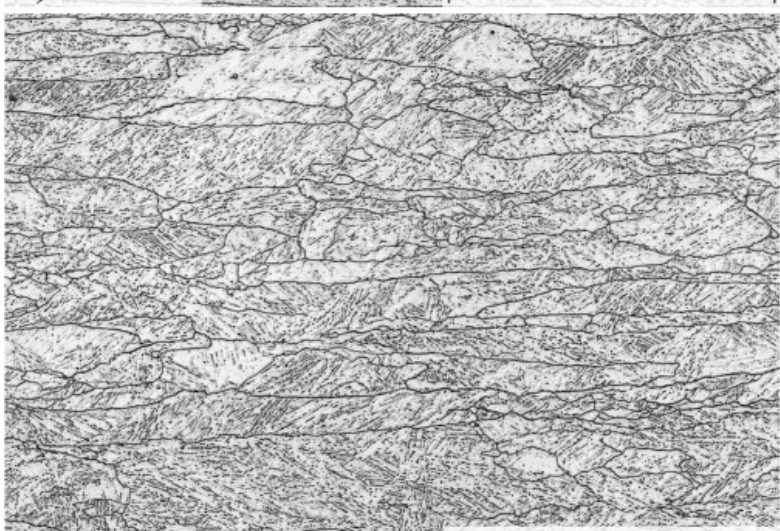

c) B920 $50 \mu \mathrm{m}$

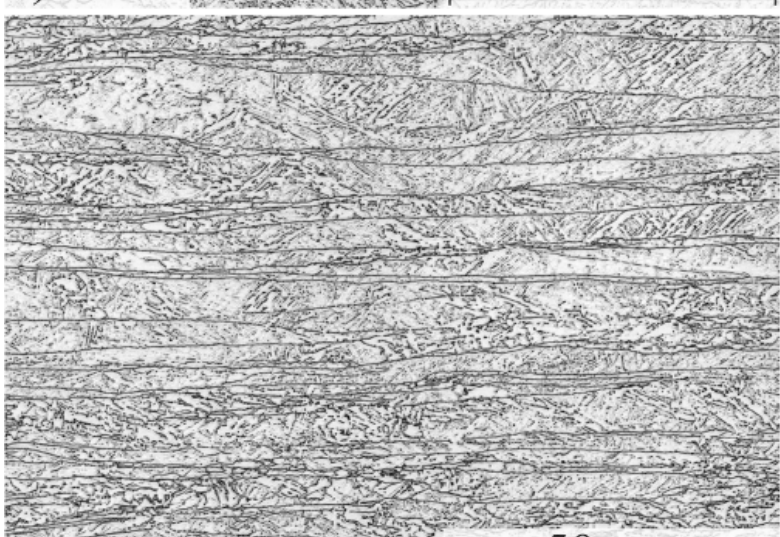

d) $\mathrm{B} 820$

$50 \mu \mathrm{m}$

Fig. 1. LSCM images of prior austenite morphologies following etching with Picric acid: (a) A920, (b) A820, (c) B920 and (d) B820 at the quarter-thickness as seen in $\mathrm{RD}-\mathrm{ND}$ section
The microstructures at the mid-thickness and subsurface of the specimens as determined on the basis of FESEM observations and EBSD measurements, are listed in Table 2, and examples of characteristic microstructures are given in Figs. 2 and 3, respectively. The transformation microstructures of the specimens consisted of mixtures of quasi- or polygonal ferrite (F), granular bainite (GB), lower bainite (LB), upper bainite (UB), auto-tempered martensite (ATM) and un-tempered lath martensite (UTM).

\section{TABLE 2}

Microstructural characterisation of investigated materials at the centreline and the surface below from $50 \mu \mathrm{m}$ to $400 \mu \mathrm{m}$

\begin{tabular}{|c|c|c|c|c|}
\hline \hline \multirow{2}{*}{ Material } & \multicolumn{2}{|c|}{ Centreline } & \multicolumn{2}{c|}{ Subsurface } \\
\cline { 2 - 5 } & $\begin{array}{c}\text { Main } \\
\text { phase }\end{array}$ & $\begin{array}{c}\text { Secondary } \\
\text { phase }\end{array}$ & $\begin{array}{c}\text { Main } \\
\text { phase }\end{array}$ & $\begin{array}{c}\text { Secondary } \\
\text { phase }\end{array}$ \\
\hline A950 & ATM & UB, LB, UTM & ATM & UB, LB \\
\hline A920 & ATM & UB, LB & ATM & UB, LB \\
\hline A850 & ATM & LB, UB & ATM & UB, LB \\
\hline A830 & ATM & LB, UB & UB & ATM \\
\hline A820 & ATM & LB, UB, GB & GB & F, UB, ATM \\
\hline B920 & ATM & UB & UB & ATM, GB \\
\hline B880 & ATM & UB & UB & ATM, GB \\
\hline B840 & UB & ATM, GB & GB & UB, F \\
\hline B820 & UB & GB, ATM & GB & F, UB \\
\hline
\end{tabular}

The transformation microstructures at the centreline of the Steel A specimens consisted essentially of mixtures of bainite and martensite (Fig. 2a). On the basis of the FESEM observations, it was determined that auto-tempered lath martensite (ATM) and lower bainite (LB) were the primary transformation products, besides the presence of small fractions of upper bainite (UB) and un-tempered lath martensite (UTM). Similarly, microstructures at the centreline of Steel B mostly consisted of auto-tempered martensite with some upper bainite (Fig. 2b). As regards the subsurface microstructures, a decrease of FRT increased the incidence of granular bainite (GB) and ferrite (F) in lieu of ATM and UB, Figs. 2c-d.

Microstructures of specimens A950, A920 and A850 essentially comprised mixtures of UB, LB and ATM at the subsurfaces (50 to $400 \mu \mathrm{m}$ ). However, granular bainite (GB) is observed at least $300 \mu \mathrm{m}$ below the surface in specimen A820 (Fig. 2e). The microstructure of $\mathrm{A} 830$ below the $50 \mu \mathrm{m}$ thick subsurface layer revealed PF and GB, whereas the centreline essentially consisted of upper bainite (UB) with numerous martensite-retained austenite (MA) plates aligned parallel to the rolling direction (Fig. 2f).

Steel B with $0.04 \mathrm{Nb}$ raised the $\mathrm{T}_{\mathrm{nr}}$ temperature of the steel significantly and hence, the subsurface layer (50 to $400 \mu \mathrm{m}$ ) showed mainly upper bainite and martensite in specimens with FRTs above $880^{\circ} \mathrm{C}$, though a small fraction of granular bainite has also been noticed. In Steel B, with FRT below $840^{\circ} \mathrm{C}$, the subsurface was mainly granular bainite with some upper bainite and ferrite (Fig. 2c). A decrease of FRT further increased the incidence of softer microstructures like ferrite and granular 

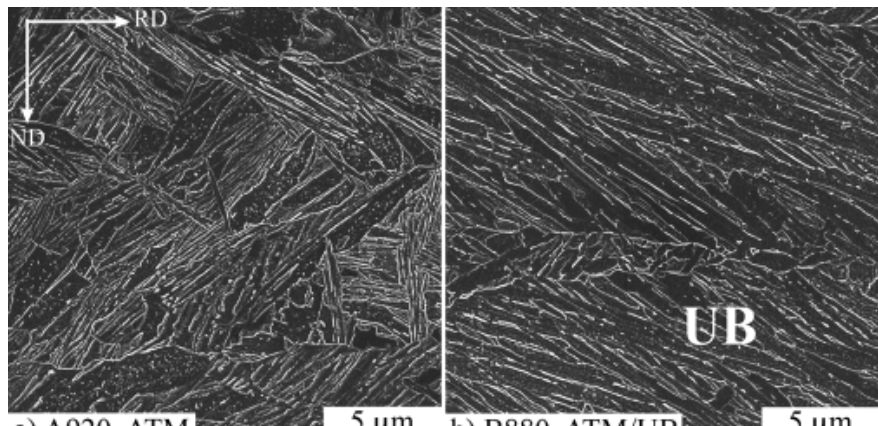

\section{a) A920, ATM}

$5 \mu \mathrm{m}$
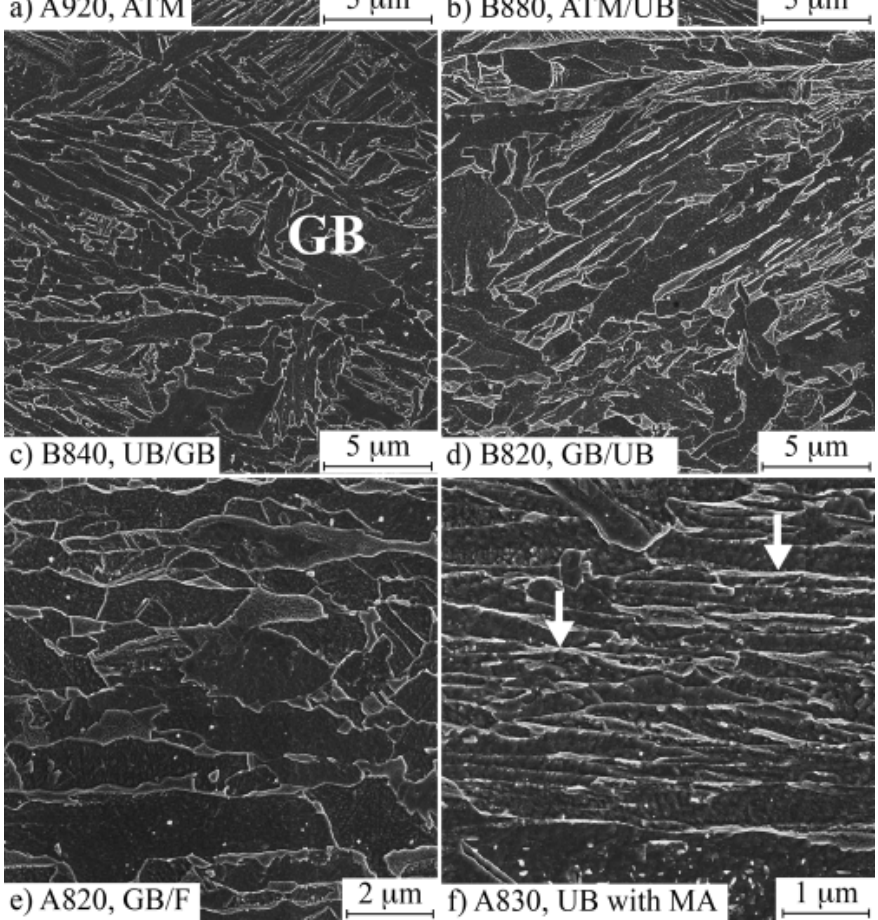

e) $\mathrm{A} 820, \mathrm{~GB} / \mathrm{F}$

$2 \mu \mathrm{m}$ A830, UB with MA

$1 \mu \mathrm{m}$

Fig. 2. Typical microstructures recorded at the centreline following etching with 2\% Nital: (a) A920: auto-tempered martensite, (b) B880: martensite and bainite, (c) B840: bainite, (d) B820: bainite and the subsurface (e) A820: granular bainite and ferrite and (f) A830: upper bainite with MA-plates (arrows)

bainite, similarly as observed in Steel A at low FRTs. In contrast to the subsurface features of Steel A, Steel B did also show upper bainite with martensite-retained austenite (MA) islands aligned parallel to the rolling direction in B840 sample.

EBSD maps and grain boundary misorientation distribution, as shown in Fig. 3, corroborated the FESEM microstructural classifications. Ferrite grain boundaries are practically randomly distributed (Fig. 3a). In granular bainite with irregular ferrite (Fig. 3b), the distribution of grain boundaries is less random as compared to ferrite grains and is revealed by a broad peak at approx. $50^{\circ}$, whereas the existence of substructure produces a peak below $15^{\circ}$. Upper bainite has a high fraction of low-angle boundaries (below $15^{\circ}$ ) and relatively low high-angle boundaries $\left(>50^{\circ}\right)$, Fig. 3c. In auto-tempered martensite (Fig. 3d) the distribution of grain boundaries is comparatively similar as in the case of upper bainite, while the fraction of high-angle boundaries $\left(>50^{\circ}\right)$ remains high.
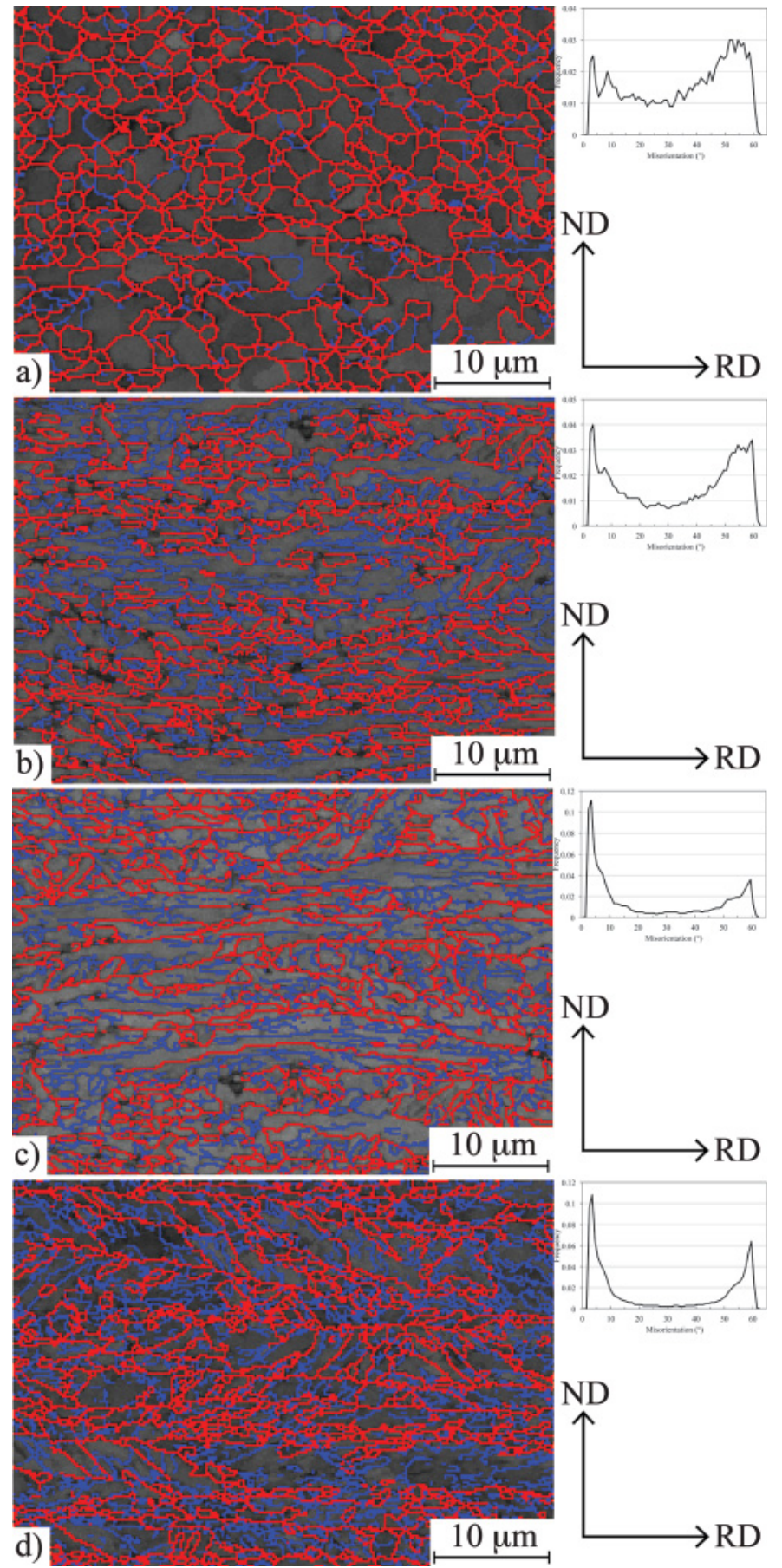

Fig. 3. Band contrast and grain boundary maps present with misorientation distributions covering angles $2.5-62.7^{\circ}$ of the areas concerned. Low-angle boundaries $\left(2.5^{\circ}-15^{\circ}\right)$ are blue and high-angle boundaries $\left(>15^{\circ}\right.$ ) are red. (a) Ferrite in B820, (b) granular bainite in A820, (c) upper bainite in A830, and (d) auto-tempered martensite in A920

\subsubsection{Mechanical properties}

The tensile property evaluation in the longitudinal direction showed reasonably high strength levels for the two steels, as depicted in Fig. 4a. The yield strength $\left(\mathrm{R}_{\mathrm{p} 0.2}\right)$ and tensile strength $\left(\mathrm{R}_{\mathrm{m}}\right)$ of studied steels vary in the ranges 980-1180 MPa and 1160-270 MPa, respectively, depending on the FRT. In general, Steel $\mathrm{A}$ (without $\mathrm{Nb}$ microalloying) showed higher $\mathrm{R}_{\mathrm{p} 0.2}$ and $\mathrm{R}_{\mathrm{m}}$ compared to that of Steel B (with $0.04 \mathrm{wt} \% \% \mathrm{Nb}$ ) irrespective 
of the FRT, as $\mathrm{Nb}$ raises the $\mathrm{T}_{\mathrm{nr}}$ temperature significantly and facilitates pancaking even at high FRTs, which may be influencing the phase transformation characteristics. Both $\mathrm{R}_{\mathrm{p} 0.2}$ and $\mathrm{R}_{\mathrm{m}}$ increased initially with the decrease in FRT as a consequence of the increased pancaking and finer packets of martensite, but decreased subsequently at lower FRTs obviously due to the formation of higher temperature transformation products and required further confirmation through $\mathrm{CCT}$ dilatation tests. The effect was more pronounced in the case of Steel A as the FRT dropped below $840^{\circ} \mathrm{C}$. The $\mathrm{R}_{\mathrm{p} 0.2} / \mathrm{R}_{\mathrm{m}}$ ratios are in the range $0.89-0.94$. Elongation to fracture $\left(\mathrm{A}_{5}\right)$ recorded on these samples varied in the range $8.6-12.0 \%$ for longitudinal specimens.

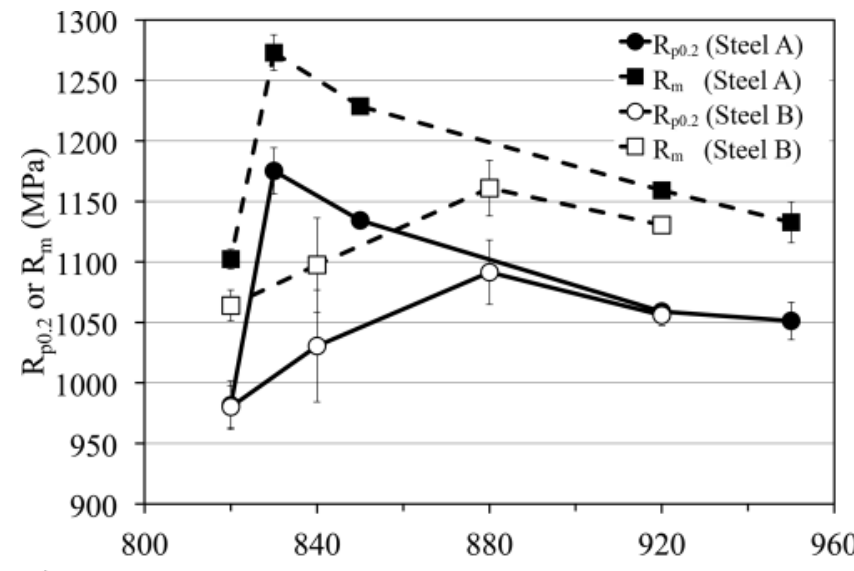

a)

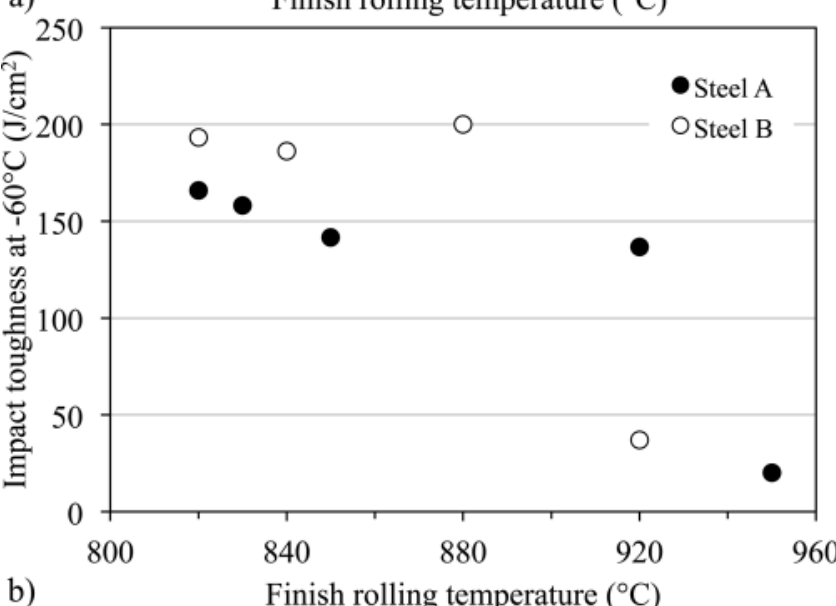

Fig. 4. Effect of FRT on mechanical properties (in longitudinal direction): (a) yield stress $\left(\mathrm{R}_{\mathrm{p} 0.2}\right)$ and tensile strength $\left(\mathrm{R}_{\mathrm{m}}\right)$ and (b) Charpy $\mathrm{V}$ impact toughness measured at $-60^{\circ} \mathrm{C}$

Fig. $4 \mathrm{~b}$ shows an example of the Charpy V impact toughness (in $\mathrm{J} / \mathrm{cm}^{2}$ ) vs. FRT measured at $-60^{\circ} \mathrm{C}$ for both the steels in the longitudinal direction. Both steels showed improvement in toughness as the FRT decreased, obviously due to the shortening and randomization of martensite laths. In particular, Steel B showed relatively higher impact energies at all FRTs, as a consequence of lower yield and tensile strengths, Fig. 4. This can be linked to the presence of upper and granular bainite in the microstructures of Steels B even at higher FRTs, Fig. 2. However, the impact toughness was slightly lower in transverse direction, irrespective of the steel type and FRT.
The bendability of the two compositions varied over a wide range depending on the FRT and corresponding subsurface microstructure, with minimum bending radii varying from as low as 2-5 times and 2-8 times the thickness for the bend axis parallel and perpendicular to the RD, respectively. In transverse bending (perpendicular to RD), sheets A830 and B840 cracked even after bending to a small angle with the largest punch radius used, i.e. $50 \mathrm{~mm}$. The minimum bending radii obtained with soft surfaces for Steels A820 and B820 were small (2.0 times thickness) in both the directions. These values can be considered as satisfactory for the strength level concerned.

\subsection{CCT diagrams}

CCT diagrams plotted from the dilatation data of Steels $\mathrm{A}$ and $\mathrm{B}$, both in the unstrained and $3 \times 0.2$ strained conditions, are presented in Figs. 5a-b. In unstrained condition, the phase transformation (PT) start temperatures were quite similar for both steels at the high linear cooling rates, $30-70^{\circ} \mathrm{C} / \mathrm{s}$. However, with further decrease in cooling rate, there is an appreciable difference in the phase transformation start temperatures, with Steel B showing higher transformation temperatures due to the presence of $\mathrm{Nb}$, which is also a strong carbide and ferrite former. As a consequence, Vickers hardness data showed marginally lower or comparable hardness for Steel B at all cooling rates. Temperatures marking the completion of phase transformation are somewhat lower for Steel A, though there is hardly any difference at the $50 \% \mathrm{PT}$, thus further corroborating the marginally higher hardness of Steel A. As can be discerned from Fig. 5a-b, in unstrained condition, cooling rates beyond about $30^{\circ} \mathrm{C} / \mathrm{s}$ should result in lower bainite and martensite, irrespective of the steel type. In case of direct quenching, cooling rates may vary in the range $50-70^{\circ} \mathrm{C} / \mathrm{s}$ for strip thickness varying in the range $6-8 \mathrm{~mm}$ and hence this part of the CCT diagram is of interest here.

An example of the influence of straining in the austenite in the $T_{n r}$ regime on the phase transformation characteristics is depicted in Fig. 5a-b corresponding to the CCT dilatation following $3 \times 0.2$ straining at $850^{\circ} \mathrm{C}$, as described earlier. It is obvious that there is no significant change in the transformation temperatures of Steel A at $50-70^{\circ} \mathrm{C}$ for this FRT, but there is a marginal decrease in the transformation temperatures at lower cooling rates with a concomitant increase in hardness compared to that of the unstrained specimens. In sharp contrast, Steel B with $\mathrm{Nb}$ microalloying showed an appreciable increase in the phase transformation temperatures practically at all cooling rates, Fig. 5b. The effect is more obvious at the highest cooling rates $\left(30-70^{\circ} \mathrm{C} / \mathrm{s}\right)$, corroborating the influence of high $\mathrm{R}_{\text {tot }}(\sim 64 \%)$ on the strain induced high temperature transformation products. Even though the effect is not that appreciable at the lower cooling rates $\left(2-10^{\circ} \mathrm{C} / \mathrm{s}\right)$, the hardness has dropped significantly at lower cooling rates. In contrast, hardness values do not show any particular trend (sometimes in opposite direction) in the cooling rate range $30-70^{\circ} \mathrm{C} / \mathrm{s}$ following $3 \times 0.2$ straining, even though there is a large difference in the phase transformation temperatures. 

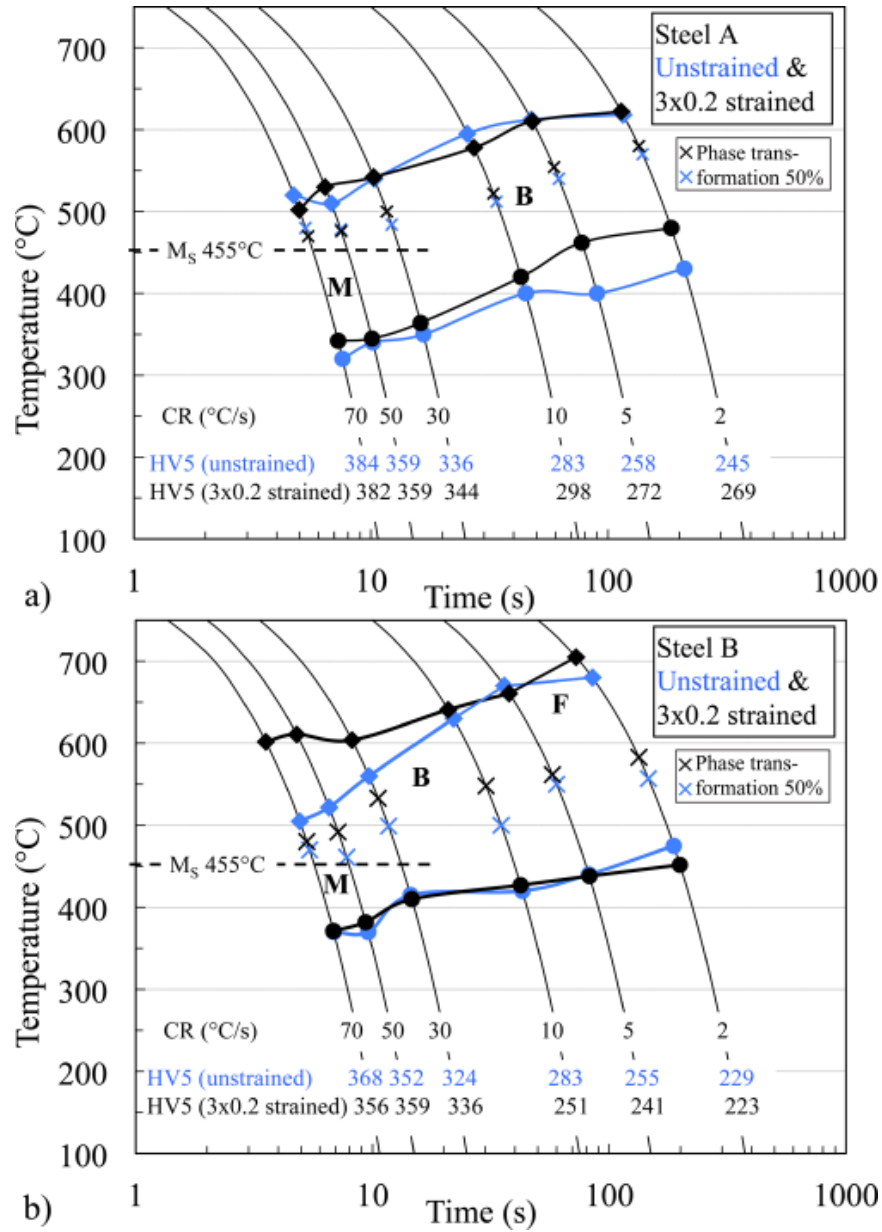

Fig. 5. CCT diagrams of (a) Steel A and (b) Steel B in both unstrained (blue) and $3 \times 0.2$ strained at $850^{\circ} \mathrm{C}$ (black) conditions. $\mathrm{M}_{\mathrm{S}}$ temperature computed using equation given in Ref. [12] is also indicated in both diagrams. (Abbreviations: $\mathrm{F}=$ Ferrite, $\mathrm{B}=$ Bainite and $\mathrm{M}=$ Martensite)

Because of this observation, it seems that the macroscopic hardness of a thermo-mechanically processed specimen is not only governed by the formed phases, but also by the size scale and distribution of the microstructural constituents.

Microstructural examination of all strained and unstrained specimens cooled at $70^{\circ} \mathrm{C} / \mathrm{s}$ are presented in Fig. 6a-d. While the microstructures of Steel A (both strained and unstrained; Figs. 6a and 6c) and also Steel B in unstrained condition (Fig. 6b) appear mostly martensitic, the microstructure of Steel B in strained condition (Fig. 6d) displays a fine mixture of bainite and martensite, which clearly confirms an appreciable increase in the bainite phase field in the CCT diagram of Steel B at high cooling rates as a result of $\mathrm{Nb}$ microalloying (Fig. 5b).

The results of CCT diagrams further confirm the microstructures observed in the hot rolled strips both at the core and subsurface regions and variation in mechanical properties as a function of FRT. The results are particularly interesting for Steel B with $\mathrm{Nb}$ microalloying, which showed relatively lower yield and tensile strengths with a concomitant increase in toughness at $-60^{\circ} \mathrm{C}$.
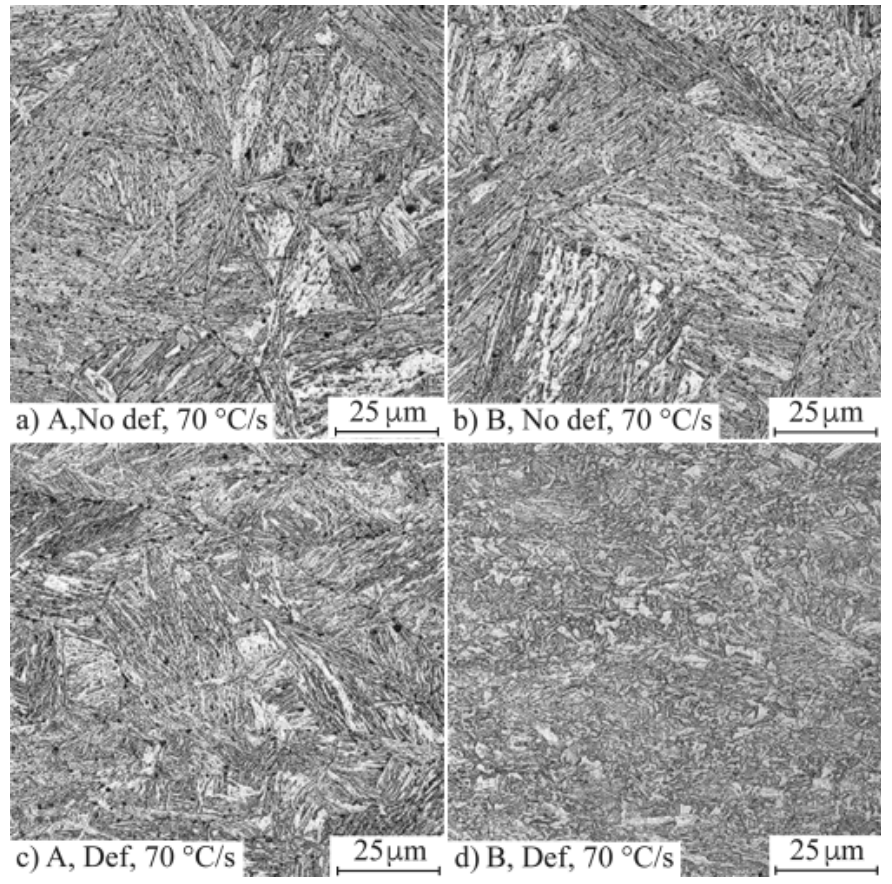

Fig. 6. Typical microstructures of CCT specimens cooled at $70^{\circ} \mathrm{C} / \mathrm{s}$ following etching with Nital: (a) Steel A: unstrained, (b) Steel B: unstrained, (c) Steel A: $3 \times 0.2$ strained at $850^{\circ} \mathrm{C}$ and (d) Steel B: $3 \times 0.2$ strained at $850^{\circ} \mathrm{C}$

\section{Discussion}

The yield and tensile strength increased with increasing reduction in the non-recrystallization regime, $\mathrm{R}_{\text {tot }}$, up to $66 \%$ followed by a decrease in strength due to a larger fraction of bainite in Steel A. Therefore, strengthening can be attributed to the observed refinement and randomization of the lath, block and packet size [17-19], corresponding to the change from pure martensite to lower bainite and auto-tempered martensite mixtures [20]. However, it is difficult to separate the effects of these features from each other, as they are very interrelated. Similar results have been observed for Steel B, where higher FRT led to the formation of ATM and UB microstructures at subsurfaces, obviously due to the strong influence of $\mathrm{Nb}$ on raising the $\mathrm{T}_{\mathrm{nr}}$ temperature, resulting in higher yield strengths than that obtained with lower FRT resulting in GB microstructure, as also corroborated by the CCT diagrams. In Fig. $4 \mathrm{a}$, it can be seen that strength decreases with FRT lower than $880^{\circ} \mathrm{C}$, which trend is opposite to that observed on Steel A without $\mathrm{Nb}$ microalloying. However, the yield strength of Steel A dropped significantly to the level of Steel B at the FRT of $820^{\circ} \mathrm{C}$. Elongation to fracture values of the materials correlate inversely with tensile strength as typical of ferritic steels.

A comparison of Steels A and B clearly reveals the effect of $\mathrm{Nb}$ on yield and tensile strength at different FRTs. As FRT decreases, the degree of deformation of the austenite increases down to the temperature at which the strain in the austenite is sufficient to induce the formation of significant amounts of granular bainite. Further reductions in FRT then cause a decrease in the yield and tensile strengths. However, up to a point depending 
on the steel type, a reduction in FRT increases strength as discussed above. In the case of the $\mathrm{Nb}$-alloyed Steel B the critical temperature giving the maximum strength is roughly $880^{\circ} \mathrm{C}$, whereas in the $\mathrm{Nb}$-free Steel $\mathrm{A}$ it is $830^{\circ} \mathrm{C}$ because, for a given FRT, less strain is accumulated in the absence of $\mathrm{Nb}$, i.e. $\mathrm{R}_{\text {tot }}$ is smaller, see Table 1.

While Steel A was rolled to a thickness of $6 \mathrm{~mm}$, Steel B was rolled down to $8 \mathrm{~mm}$. Therefore, it might also affect the grain structure. Had the material B been similarly rolled down to $6 \mathrm{~mm}$ thickness, the extent of pancaking would have been marginally higher. The studied Steel B was microalloyed with niobium, which strongly affects the recrystallization behaviour of austenite during hot rolling, particularly in the temperature range below the recrystallization limit temperature in the $\mathrm{T}_{\mathrm{nr}}$ regime, $1014^{\circ} \mathrm{C}$ to $858^{\circ} \mathrm{C}$ (calculated using $\mathrm{T}_{\mathrm{nr}}$ equation from Ref. [21]. Due to the retardation of austenite recrystallization kinetics, pancaked austenite grain structure can be obtained at relatively high temperatures [22]. Though molybdenum is known to have a strong retarding influence on the recrystallization kinetics of steels, its influence can be less effective in the presence of other microalloying elements with stronger influence on recrystallization rates, such as $\mathrm{Nb}$ [21]. Hence, it is the presence of $\mathrm{Nb}$ in Steel B that accounts for the highly pancaked prior austenite grain structure present in Steel B even with a FRT of $920^{\circ} \mathrm{C}$, where $\mathrm{R}_{\text {tot }}$ was $52 \%$. On the other hand, in Steel A without $\mathrm{Nb}$ the $\mathrm{R}_{\text {tot }}$ was only $38 \%$ at the FRT of $920^{\circ} \mathrm{C}$, see Table 1 .

The effect of low-temperature finish rolling, i.e. pancaking, depends on the hardenability of the steel. It is well established that diffusion controlled transformations are strongly affected by austenite deformation, such that if the steel composition and cooling rate result in the formation of ferrite, the phase transformation start temperature is increased, i.e. the hardenability is decreased by austenite deformation [9]. Similar results have been found by Taylor and Hansen [23], where lowering FRT (from 980 to $870^{\circ} \mathrm{C}$ ) was found to reduce the hardenability of a $0.2 \mathrm{C}-0.6 \mathrm{Mn}-0.5 \mathrm{Mo}-0.001 \mathrm{~B}$ steel.

Deformation of austenite below its no-recrystallization temperature has been observed to enhance bainite formation, i.e. shift the C-curve to shorter times in the time-temperaturetransformation (TTT) diagram [24]. This indicates that lowering the FRT should lead to the formation of bainite at higher temperatures resulting in higher volume fractions of granular bainite instead of lath-like bainite. In the present cases, increasing $\mathrm{R}_{\text {tot }}$ promoted the formation of bainitic microstructures instead of martensitic ones, although polygonal ferrite can also be seen near the strip surface after the highest $\mathrm{R}_{\text {tot }}$ obviously as a result of the strain induced transformation due to lower than the average temperatures at strip surfaces. This can be observed from the data in Table 2 and the micrographs in Fig. 2e. The observed higher impact energies in Steel B can be linked to the presence of upper and granular bainite in the microstructures of Steels B even at higher FRTs.

During hot rolling, the steel temperature near the surface fluctuates strongly as the material flows into and out of the roll gap. Contact with the colder rolls rapidly chills the subsurface regions of the strip [25] as they enter the roll gap, while on leaving the roll gap, heat flow from deeper in the material rapidly reheats the subsurface layers. Thus, it is possible that in case of low FRT the surface temperature can drop momentarily to levels where the nucleation and limited growth of ferrite and/or granular bainite can occur even during hot rolling, whereas this would not occur for higher FRT. Of course the development of the microstructure is very complicated as some reversion to austenite can occur during the rapid reheating of the surface that occurs as the strip leaves the roll gap. Such effects can be responsible for the complex nature of the microstructures nearest to the strip surface. As a consequence, minimum bending radii obtained with soft surfaces for both steels, particularly at a FRT of $820^{\circ} \mathrm{C}$ were quite small (2.0 times thickness) in both the directions.

The above effects are probably also reinforced by the roll bite strain, i.e. strain-induced ferrite formation [26,27]. Mintz et al. [28] have shown that even small strains are sufficient for the production of such ferrite and it appears at temperatures ranging from just below the $\mathrm{Ae}_{3}$ down to the $\mathrm{Ar}_{3}$ temperature of the undeformed structure. There is also evidence that deformationinduced ferrite can form dynamically somewhat above the $\mathrm{Ae}_{3}$ temperature [29].

\section{Conclusions}

The purpose of this research was to explore the relationship of $\mathrm{Nb}$ microalloying between microstructure of hot-rolled and direct quenched ultrahigh-strength steels. The main observations and conclusions of the work can be summarized as follows:

- An increase in the total reduction in the non-recrystallization region $\left(\mathrm{R}_{\text {tot }}\right)$ in conjunction with a lowering of the finishing rolling temperature and microalloying with niobium increased the austenite pancaking.

- A decrease of FRT increased the formation of softer microstructures such as ferrite (F) and granular bainite (GB) in the subsurface layers. The microstructures at the centreline consisted mainly of auto-tempered martensite (ATM) with some bainite, though here too, a decrease of FRT increased the fractions of GB and F at the expense of ATM and UB.

- There was a tendency for the yield stress and tensile strength of the steel sheets to decrease on lowering FRT when F and GB formed at the surface while elongation to fracture did not increase. Similar the toughness and bendability improved while F and GB formed at the surface.

- $\quad \mathrm{Nb}$ microalloying and deformation promoted bainite formation in CCT simulations.

\section{Acknowledgements}

The financial support of the Finnish Funding Agency for Technology and Innovation (Tekes) in the Breakthrough Steels and Applications Program of the Finnish Metals and Engineering Competence Cluster (FIMECC Ltd) is gratefully acknowledged. 


\section{REFERENCES}

[1] P.P. Suikkanen, J.I. Kömi, Microstructure, Mater. Sci. Forum. 783-786, 246-251 (2014).

[2] A.J. Kaijalainen, P. Suikkanen, L.P. Karjalainen, J.J. Jonas, Metall. Mater. Trans. A. 45, 1273-1283 (2014).

[3] A.J. Kaijalainen, P.P. Suikkanen, T.J. Limnell, L.P. Karjalainen, J.I. Kömi, D.A. Porter, J. Alloys Compd. 577, S642-S648 (2013).

[4] H. Asahi, E. Tsuru, T. Hara, M. Sugiyama, Y. Terada, H. Shinada, et al., Int. J. Offshore Polar Eng. 14, 36-41 (2004).

[5] M. Hemmilä, R. Laitinen, T. Liimatainen, D.A. Porter, in: Proc. 1st Int. Conf. "Super-High Strength Steels", Associazone Italiana di Metallurgica - AIM, Rome (2005).

[6] J. Heikkala, A. Väisänen, in: Proc. 11th Bienn. Conf. Eng. Syst. Des. Anal., (2012).

[7] A.J. Kaijalainen, P.P. Suikkanen, L.P. Karjalainen, D.A. Porter, Mater. Sci. Eng. A. 654, 151-160 (2016).

[8] A.J. Kaijalainen, M. Liimatainen, V. Kesti, J. Heikkala, T. Liimatainen, D.A. Porter, Metall. Mater. Trans. A. 47, 4175-4188 (2016).

[9] I. Kozasu, in: T. Chandra, T. Sakai (Eds.), Int. Conf. Thermomechanical Process. Steels Other Mater., The Minerals, Metals \& Materials Society, Wollongong, 47-55, (1997).

[10] W. Steven, A.G. Haynes, J. Iron Steel Inst. 183, 349-359 (1956).

[11] F.B. Pickering, in: M. Korchysky (Ed.), Microalloying '75, Union Carbide Corporation, Washinghton DC, 9-31, (1977).

[12] Stuhlmann W., Härterei Tech. Mitteilungen. 6, 31-48 (1954).

[13] G.D. Wang, Z.D. Wang, J.B. Qu, Z.Y. Jiang, X.H. Liu, in: T. Chandra, T. Sakai (Eds.), Int. Conf. Thermomechanical Process. Steels Other Mater., The Minerals, Metals \& Materials Society, Wollongong, 717-723, (1997).
[14] A. Brownrigg, P. Curcio, R. Boelen, Metallography. 8, 529-533, (1975).

[15] R.L. Higginson, C.M. Sellars, Worked Examples in Quantitative Metallography, (2003) Maney, London.

[16] S. Zajac, V. Schwinn, K.-H. Tacke, Mater. Sci. Forum. 500-501, 387-394 (2005).

[17] G. Langford, M. Cohen, Metall. Mater. Trans. 1, 1478-1480 (1970).

[18] P. Brozzo, G. Buzzichelli, A. Mascanzoni, M. Mirabile, Met. Sci. 11, 123-130 (1977).

[19] K. Zhu, O. Bouaziz, C. Oberbillig, M. Huang, Mater. Sci. Eng. A. 527, 6614-6619 (2010).

[20] A.J. DeArdo, ISIJ Int. 35, 946-954 (1995).

[21] R. Barbosa, F. Boratto, S. Yue, J.J. Jonas, in: A.J. Deardo (Ed.), Process. Microstruct. Prop. HSLA Steels, TMS, Warrendale, 51-61, 1988.

[22] F.C. Campbell, Elements of Metallurgy and Engineering Alloys, 2008 ASM International, Materials Park, Ohio.

[23] K.A. Taylor, S.S. Hansen, in: Heat Treat. Surf. Eng. New Technol. Pract. Appl., Chicago 1988, 137-142.

[24] M.C. Somani, D.A. Porter, J.M. Pyykkönen, J.M. Tarkka, J.I. Kömi, T.A. Intonen, et al., in: Int. Conf. Microalloyed Steels Process. Microstruct. Prop. Perform., Association for Iron \& Steel Technology, Pittsburgh 2007, 95-106.

[25] J. Pyykkönen, P. Suikkanen, M.C. Somani, D.A. Porter, Matériaux Tech. 100, S1-17-19 (2012).

[26] K. Hulka, J.M. Gray, F. Heisterkamp, Niobium Technical Report 16/90, (1990).

[27] Y.E. Smith, C.A. Siebert, Metall. Trans. 2, 1711-725 (1971).

[28] B. Mintz, J. Lewis, J.J. Jonas, Mater. Sci. Technol. 13, 379-388 (1997).

[29] H. Yada, C.M. Li, H. Yamagata, ISIJ Int. 40, 200-206 (2000). 